\title{
Empirical Analysis and Predictions of Civil Aviation Passenger Traffic Based on ARIMA model
}

\author{
Xiaoxia $\mathrm{ZHAO}^{1, \text { a }}$, Hongxia $\mathrm{ZHAO}^{2}$ \\ ${ }^{1}$ School of Economics and Management Beijing, Jiaotong University, Beijing 100044, China \\ ${ }^{2}$ Dean's Office, Shijiazhuang Information Engineering Vocational College, Shijiazhuang 050035 , \\ China \\ ahaoxiaoxia@163.com
}

Keywords: Civil Aviation; Passenger Traffic; ARIMA Model; Prediction

\begin{abstract}
With the help of statistical software Eview6.0, qualitative analysis is carried out of China's civil aviation passenger traffic since reform and opening up. It is found that China's civil aviation passenger traffic development experienced three stages: slow development stage from 1978 to1990, relatively rapid development stage from 1991 to 2003 and rapid development stage from 2004 until now. By carrying on the empirical analysis and forecasting through constructing the ARIMA model of passenger traffic, it shows that ARIMA $(2,2,1)$ has a better fitting effect on the original data sequence and can undertake short-term forecast of passenger traffic, which provide data support for civil aviation passenger traffic regulation.
\end{abstract}

\section{Background analysis}

\section{Present development situation of civil aviation}

Since the founding of new China, civil aviation has made great progress in our country. Especially after reform and opening-up, market reform is carried out step by step over 30 years. In our country civil aviation, air transport, general aviation, fleet size, route layout, laws and regulations construction, and transportation security and so on has achieved sustained and rapid development, having made remarkable achievements. [1]Since 2005, China's air transport total turnover ranked second in the world, and keeps this position for three consecutive years, thus becoming a veritable air transport powers in the world. In China's economic and social development and the process of world civil aviation development, air transport plays a more and more important role.

1) Sustained and rapid growth in domestic air transport

By the end of 2008, China's civil aviation industry has complete transportation turnover reached 36.1 billion ton kilometers, 185 million passengers and 3.96 million tons of goods, respectively 120.5 times, 80.5 times and 120.5 times of that in 197. [2]From 1978 to 2007, average annual growth are $17.9 \%, 16.3 \%$ and $15.4 \%$ respectively. The continuing growth of air transport and the growing industry scale makes the civil aviation more and more important in our national economy.

\section{2) Significant progress the international air transport made}

During the tenth five-year plan, China signed an unprecedented open bilateral air service agreements with the United States, Germany, France, Britain, Australia, Thailand and other countries and regions, which marked the international air transport policy has a new development in our country. China's domestic airlines dare to participate in international competition and open up more and more international routes. [3]In 1978, our country had only 12 international routes, connecting Soviet union, north Korea, Pakistan, France and so on, only 13 countries, In 2007 2008 winter and spring season, our domestic airline operates regular passenger routes to 48 countries, 92 cities, 1441 round-trip flights a week. Regular shipping has routes to 28 cities in 22 countries, 217 flights per week. Rapid growths happen in international air traffic in China.

3) Route network continue to expand, complete air transport network preliminary formed

By the end of 2008, 15 airlines has a total of flight to 92 cities in 48, 1307 a week regular passenger flights and 204 regular cargo flights. Route network layout is more reasonable, initially 
formed air transportation network system that connects international gateway cities such as Beijing, Shanghai, Guangzhou as the center, connecting the world's major countries and regions in the world, which greatly promote the formation of a unified national market and the process of global economic integration. Fleet size expanded rapidly, which improve the ability of air transport. By the end of 2008, China's civil aviation has 1131 transport aircraft (including 73 small aircraft, 56 all-cargo aircraft), 805 general aviation aircraft. Main transport aircraft are of advanced technology level in the world with good economic performance. Update and expand of fleet not only greatly improve the quality of the air transport capacity and transport in our country, but also can provide passengers with more secure, more comfortable, more cheap service.

\section{Status quo analysis of passenger traffic}

The civil aviation passenger traffic is the number of passengers that the civil aviation actual delivered in a certain period of time. [4] It is the quantitative index that reflects the civil aviation transportation industry national economy and the daily lives of the people, an important indicator to establish and check the civil aviation transportation production plan, the civil aviation transportation development scale and speed.

In order to understand the development trend of China's civil aviation transportation industry better and better grasp the development trend of China's civil aviation passenger traffic, the current situation of the development of China's civil aviation passenger traffic is simply analyzed of the period 1978-2013.

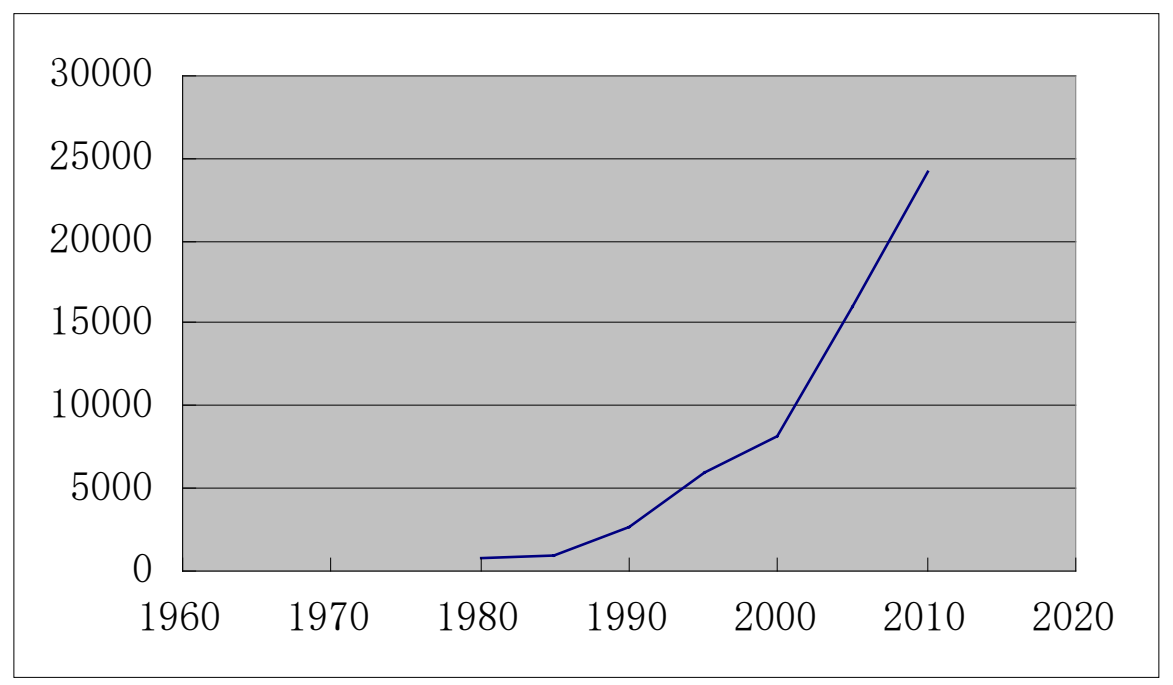

Figure 1 China’s civil aviation passenger traffic changing trend during 1978-2013

Table 1 Passenger traffic in China during the period 1978-2013

\begin{tabular}{|c|c|c|c|c|c|}
\hline Year & Passenger traffic & Year & Passenger traffic & Year & Passenger traffic \\
\hline 1978 & 231 & 1990 & 1660 & 2002 & 8594 \\
\hline 1979 & 298 & 1991 & 2178 & 2003 & 8759 \\
\hline 1980 & 343 & 1992 & 2886 & 2004 & 12123 \\
\hline 1981 & 401 & 1993 & 3383 & 2005 & 13827 \\
\hline 1982 & 445 & 1994 & 4039 & 2006 & 15968 \\
\hline 1983 & 391 & 1995 & 5117 & 2007 & 18576 \\
\hline 1984 & 554 & 1996 & 5555 & 2008 & 19251 \\
\hline 1985 & 747 & 1997 & 5630 & 2009 & 23052 \\
\hline 1986 & 998 & 1998 & 5755 & 2010 & 26769 \\
\hline 1987 & 1310 & 1999 & 6094 & 2011 & 29317 \\
\hline 1988 & 1442 & 2000 & 6722 & 2012 & 31936 \\
\hline 1989 & 1283 & 2001 & 7524 & 2013 & 35397 \\
\hline
\end{tabular}

Note: data from http://data.stats.gov.cn/index

As can be seen from the figure 1, the civil aviation transportation development of our country is very slow during the period of 1978 to 1990; in the period 1989-1990 China's civil aviation passenger traffic even ads appeared a trend of sharp decline. [5]During 1990-2003, China's civil 
aviation transportation development began a rapid development, the civil aviation passenger traffic greatly improved. Since 2003, our country civil aviation passenger traffic development speed up obviously, passenger traffic started to increase, which is consistent with our country economy fast development since 2000. By the end of 2013, China's civil aviation passenger traffic volume is 353.97 million, 153 times more than in 1978. The civil aviation passenger traffic growth is a lot of times faster of the national economic growth over the same period, and much faster than the overall development velocity of civil aviation transportation industry and the world civil aviation.

\section{Introduction and building of the model}

\section{ARIMA model introduction}

ARIMA (Autoregressive Integrated Moving Aver - age) model is the summation regression moving average model, which is time series prediction method put forward by Box and Jenkins in the 1970s. It is also known as B - J model, berks-Jenkins method. [6]The modeling idea is to take the sequence constituted by the changes of predicting the formation object over time, and use the corresponding mathematical model to approximate description. Through the analysis of the corresponding mathematical model, we can understand of the internal structure of the dynamic data and complex features more essentially so as to achieve the best prediction in the sense of minimum variance.

\section{Building of ARIMA (p, d, q) model}

\section{1) Data smooth processing}

Using ARIMA model for time series modeling and forecasting is based on the basis of the original sequence is stationary random sequence. And in the actual forecast process, the original time series can often be periodic and trend change, so need to be smooth, namely on the d order by period (the season) difference.

The figure 1 shows that during 1990-2013 in China's civil aviation passenger increased. In order to eliminate the trend, at the same time reduce the volatility sequences, first order difference of the original sequence $Y_{t}$, first plan for the corresponding difference sequences, taking the difference operator as $\nabla Y_{t}$, namely $\nabla Y_{t}=Y_{t}-Y_{t-1} \cdot \nabla$ is difference operator. The conduct difference sequence of the sequence diagram $\nabla Y_{t}$, is shown in figure 2 .

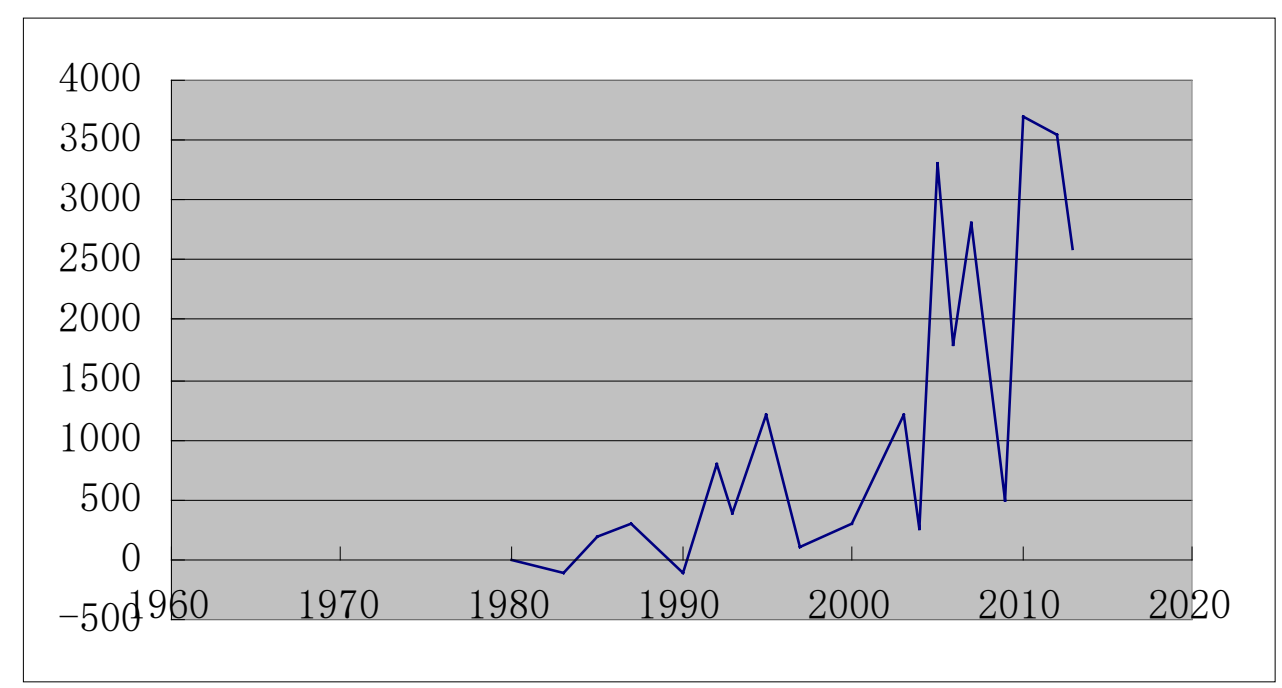

Figure 2 First order difference sequence diagrams of China’s civil aviation passenger during 1990-2013

The figure 2 shows that during 1990-2013, the first order difference sequence $\nabla Y_{t}$ of China's civil aviation passenger traffic is in periodical stable state, namely stable during 1990-2003, 2004-2013, but increase during 1990-2013. So, figure out difference once again for the first order difference sequence $\nabla Y_{t}$, get the second order difference sequence $\nabla^{2} Y_{t}$, namely $\nabla^{2} Y_{t}=\nabla Y_{t}-\nabla Y_{t-1}$. 


\section{2) ARIMA model identification}

Related model identification is the basic tool of analysis, autocorrelation function and partial autocorrelation function of stationary sequence of sample $Y_{t}$. [7]By examining their truncation, trailing and periodicity to determine what series model fitting is more appropriate. Therefore, after the observation after an order by phase difference of stationary sequence $Y_{t}$ of autocorrelation function and partial autocorrelation function, it can be found that both the sequences are of shadow. Through the above analysis, two groups of model are preliminary selected:

$\operatorname{ARIMA}(1,2,1)$

ARIMA $(2,2,1)$

3) ARIMA model parameter estimation and testing

The order number was determined by the model identification of, let's start to estimate parameters of the above two kinds of $\operatorname{ARIMA}(1,2,1)$ model and $\operatorname{ARIMA}(2,2,1)$.

Through the parameter estimation, we should examine the suitability of ARIMA model, namely do white noise inspection to the residual sequence of the model.

Methods commonly used for pure random to determine whether a residual sequence is residual sequence of card test. Test of the null hypothesis is the residual sequence $e_{t}$ is independent of each other. Residual error sequence of autocorrelation function is:

$$
r_{k}(\mathrm{e})=\frac{\sum_{t=k+1}^{n} e_{t} e_{t-k}}{\sum_{t=1}^{n} e_{t}^{2}} \quad k=1,2, \cdots, m
$$

Test statistics is:

$$
Q=n(\mathrm{n}+2) \sum_{k=1}^{m} \frac{r_{k}^{2}(\mathrm{e})}{n-k}
$$

Under null hypothesis, $\mathrm{Q}$ obeys the distribution of $\chi^{2}(\mathrm{~m}-\mathrm{p}-\mathrm{q})$. For a given confidence level1- $\alpha$, if

$$
Q \leq \chi_{\alpha}^{2}(\mathrm{~m}-\mathrm{p}-\mathrm{q})
$$

Cannot refuse the original hypothesis that residual sequence is independent then the inspection pass; otherwise inspection cannot pass.

But after carefully comparing the size of the autocorrelation coefficient of the model, it is found that the absolute value of correlation coefficient of $\operatorname{ARIMA}(2,2,1)$ is mostly close to zero. So we think the ARIMA $(2,2,1)$ model is better than that of ARIMA $(1,2,1)$ model and its expansion as follows:

$$
\left(1+1.3125 B+0.6564 B^{2}\right)(1+B)^{2} Y_{t}=(1+0.7772 B) \mathrm{u}_{t}
$$

\section{Analysis and prediction}

Fitting result of ARIMA (2, 2, 1)

Choose according to the model of ARIMA $(2,2,1)$, use the statistical software Eview6.1 fitting forecast inspection passenger quantity in China airline during 1978-2013, the inspection is satisfactory

\section{Predicted results}

Through figuring ARIMA $(2,2,1)$ model's fitting prediction, it is showed that the model is an ideal model, thus can be short-term prediction by using the model, namely predict China's civil aviation passenger traffic in 2014 and 2015, the results are 381.62 million and 411.44 million respectively. 


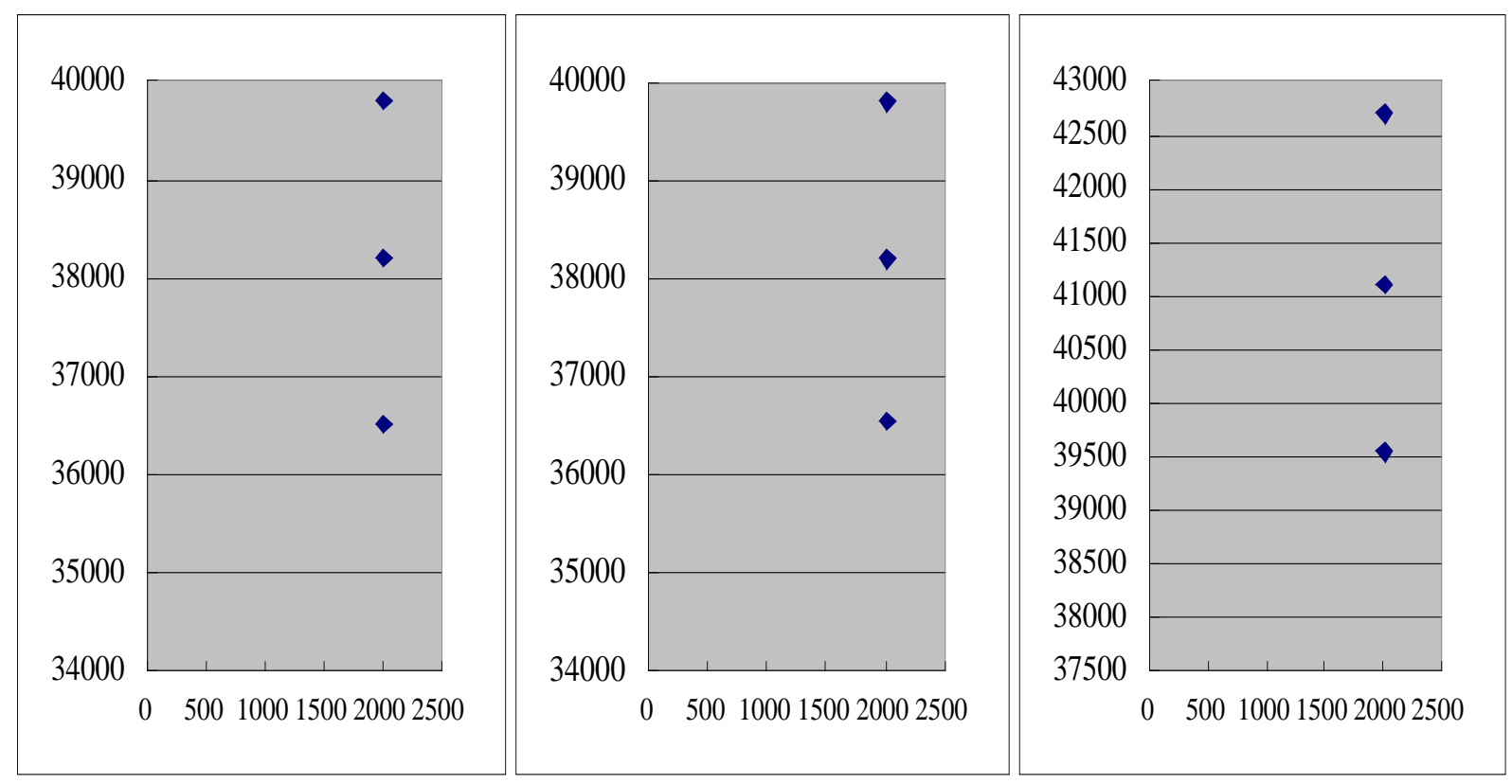

Figure 3 Predicted value of ARIMA $(2,2,1)$ model

\section{Summary}

With the help of statistical software Eview6.0, this article found that China's civil aviation passenger traffic development went through three processes. During 1978-1990 China's civil aviation passenger traffic development is still at the initial stage of slow development; from 1991 to 2003, China's civil aviation passenger traffic development entered rapid development phase; aviation passenger traffic began a stage of rapid development since 2004 in our country. Through empirical analysis of passenger traffic data, this article build the ARIMA model, whose results show that this article build ARIMA $(2,2,1)$ of the original data sequence has a better fitting effect. This paper use the ARIMA $(2,2,1)$ model to carry on the forecast passenger traffic in our country in 2013, the forecast results is satisfying.

\section{References}

[1] Ji Yuezhi, Qin Xiwen. Analysis of Factors Related to Passenger Traffic [J]. Practice and Understanding of Mathematics, 2012, 42 (24): 175-183.

[2] Cheng Xiaokang. Research and Application of the Passenger Traffic Forecast Model Analysis Based on SVR [J]. Journal of Sichuan University, 200845 (3): 527-531.

[3] Zhang Yan, Miaogang. Multivariate Linear Regression Analysis of Passenger Traffic[J]. Information science and control engineering, 2012, 33 (8): 81-86.

[4] Lijie, Wang Ke. Highway Freight Volume Forecasting Method based on Generalized Regression Neural Network Study [J]. Journal of traffic and computers, 2007, 3 (25): 131-133.

[5] Wangcui. Passenger Traffic Forecast Method Research based on the Grey Theory and RBF Neural Network [D]. Beijing Jiaotong University, 2008.

[6] Wu Xuan. Air Traffic Short-term Prediction Model based on BP Neural Network [J]. Journal of $\mathrm{Xi}$ 'an university of electronic science and technology (social science edition), 2007 (03). 